\title{
Planned Activity Repeat Frequency Ratio
}

National Cancer Institute

\section{Source}

National Cancer Institute. Planned Activity Repeat Frequency Ratio. NCI Thesaurus. Code C94002.

A ratio representing the number of occurrences of a planned activity within a given time period. 